\title{
LAS CONDESAS VIUDAS DE CIRAT Y VILLAFRANQUEZA: PAPEL ACTIVO EN LA \\ LUCHA POR SUS INTERESES FAMILIARES (SIGLO XVII)
}

\author{
THE WIDOW COUNTESSES OF CIRAT AND VILLAFRANQUEZA: ACTIVE ROLE IN THE \\ STRUGGLE OVER THEIR FAMILY INTERESTS (1TTH CENTURY)'
}

\author{
Antonio López Amores \\ Universitat Jaume I de Castellón
}

\section{RESUMEN}

Dentro del limitado y taxativo marco de la sociedad del Antiguo Régimen, la mujer adolecía de una característica situación de marcada inferioridad respecto al varón. Sin embargo, la documentación ofrece casos de mujeres que desafiaron a los fuertes condicionamientos sociales, sobre todo aquéllas que pertenecían al estrato nobiliario. Presentamos aquí dos casos contrastados, protagonizados por condesas viudas, adscritas a familias nobles valencianas, que elaboraron estrategias y acciones con tal de perseguir tanto sus intereses personales como familiares. Se trata de doña Aldonsa Crespí de Valldaura, condesa de Cirat, y de doña Leonor de Paz del Río, condesa de Villafranqueza. En sus acciones, se vislumbra el impulso de proteger a su descendencia más desamparada a causa de los propios entresijos del sistema patriarcal.

Palabras clave: Género, nobleza, nobleza valenciana, Cirat, Villafranqueza, condesas, viudedad.

\section{ABSTRACT}

Inside the limited and restricted framework of the Ancien Régime society, women had a characteristic situation of inferiority regarding the male. Nonetheless, historic documentation offers several cases of women that defied the strong social boundaries, above all those who belonged to the nobility. We present here two verified cases, represented by widow countesses, who belonged to noble valencian families and who created strategies and actions focusing on pursuing their personal and familiar interests. They are doña Aldonsa Crespí de Valldaura, countess of Cirat, and doña Leonor de Paz del Río, countess of Villafranqueza. In their actions, it can be seen the impulse to protect their most helpless offspring.

Keywords: Gender, nobility, valencian nobility, Cirat, Villafranqueza, countesses, widowhood.

\footnotetext{
1 El presente artículo ve la luz gracias al programa VALi+d, de la Generalitat Valenciana. Asimismo, se enmarca dentro del proyecto de investigación, financiado por la Universitat Jaume I, P1.1A2014-13 «De pequeños hidalgos a nobles titulados. Riquezas, poder y redes clientelares de la nobleza mediterránea».
} 
Tanto por las propias obras coetáneas como por posteriores labores historiográficas, es bien sabido que las mujeres del Antiguo Régimen se encontraban insertas en un sistema que las tenía, de un modo completamente explícito y claro, como inferiores al hombre, y las supeditaba a éste en la mayoría de los ámbitos de su vida: desde el moral y jurídico hasta el reproductivo. Este estrato desfavorecido venía refrendado, sancionado y sostenido por toda una serie de notables diferencias que habían sido construidas y se construían en torno a los modelos ideales de hombre y mujer (Blutrach-Jelín, 2001: 24-25).

No obstante, a los análisis de las últimas décadas sobre la figura de la mujer noble se añaden los frutos de las últimas investigaciones que arrojan nuevos enfoques sobre los papeles desempeñados en el seno de aquel restrictivo marco. Así, tenemos constancia de que pese a hallarse presas de unas condiciones de clara inferioridad jurídica y legal, algunas mujeres llegaron a desempeñar papeles de notable importancia, llegando, en ciertas materias como el matrimonio, a superar la visibilidad de los varones e incluso evadir su control (García Hernán, 2007: 55). Y lo que resulta más importante, supieron aprovechar los resquicios que les ofrecía el sistema con tal de ampliar redes, ejercer influencia y, también, velar por sus propios intereses así como los de su familia (Blutrach-Jelín, 2011, 28-31).

Además de esta serie de diferencias y contrastes establecidos en torno a la visión de uno y otro género, es imperativo aplicar otra capa propia de la sociedad y del pensamiento cultural de la época al conjunto: la correspondiente a la diferenciación social. Con ello, ésta sirve para acrecentar las oportunidades o las desigualdades, en función de a cuál de ellas se pertenezca. Así, las mujeres de extracción social más alta -burguesía, oligarquías locales y, por supuesto, la nobleza- disponían de mayores recursos y atravesaban, con mayor frecuencia, los límites impuestos por su sociedad².

A lo largo de las siguientes líneas, fruto de nuestra labor investigadora, presentamos algunos ejemplos de mujeres que, sitas en el siglo XVII y desde una posición de relativa capacidad de acción como era la proporcionada por la viudedad, llevaron a cabo estrategias claramente proactivas con el fin de defender sus intereses personales y familiares. Presentamos a continuación dos casos contrastados que la documentación nos ha ofrecido, protagonizados por dos condesas ya viudas que, gracias a las condiciones particulares de su situación hicieron frente a sus propios desafíos: la condesa de Cirat, doña Aldonsa Crespí de Valldaura, en la perpetuación del cargo de veedor general de la costa del Reino de Valencia

2 Con tal de profundizar en uno de los ejemplos que muestra la destacada involucración de las mujeres en el desarrollo y reproducción del patriciado urbano remitimos a JARQUE MARTínEZ, Encarna (2013): «Mujer y oligarquía urbana: el papel de la mujer en los entresijos del poder zaragozano (ss. XVI-XVII)», en SALAS AusÉNS, José Antonio (coord.): Logros en femenino. Mujer y cambio social en el valle del Ebro, siglos XVI-XVIII, Zaragoza, Prensas de la Universidad de Zaragoza, Zaragoza. 
en su linaje; $y$, por otro lado, la defensa de las rentas de las que gozaba doña Leonor de Paz del Río, condesa de Villafranqueza, que posteriormente trató de trasladar a su único hijo, en un periodo de fuertes reformas fiscales por parte de la Monarquía.

\section{La condesa de Cirat y la perpetuación del cargo de veedor general de la costa}

Es necesario tener en cuenta que para el pensamiento moderno, existen dos conceptos diversos sobre el origen de la nobleza: el primero promulgaba que las virtudes que hacían a un individuo o linaje noble se hallaban insertas en su sangre y, consecuentemente, se transmitían a sus descendientes, ennobleciéndoles si sus antepasados lo habían sido; el segundo afirmaba que la virtud nobiliaria se podía encontrar no en la herencia sino en los propios méritos personales, fraguados a lo largo de toda una vida (Domínguez Ortiz, 1985: 186). En la práctica, ambos conceptos se entrelazaban con facilidad, de modo que las Casas dedicaban considerables esfuerzos a hacer acopio de los méritos de sus antepasados y, al mismo tiempo, conseguir los suyos propios (Domínguez Ortiz, 1985: 186 y Atienza Hernández, 1998: 8-10).

El caso que introducimos - protagonizado por la familia Carroz, condes de Ciratmuestra cómo estas dos visiones, sólo contrapuestas en la teoría, se imbrican con soltura, dejando al descubierto algunas de las técnicas empleadas por la familia con tal de consolidar su posición, hacer frente a diversas penurias y, en caso de ser posible, engrandecer su nombre. Al mismo tiempo, podemos contemplar la labor realizada por las mujeres del linaje con tal de asegurar la supervivencia de otras mujeres en situación desfavorecida, así como para servir de eslabón a la hora de transmitir los cargos y oficios que contribuían a ensalzar el nombre de la Casa.

Trataremos a continuación, en nuestra aproximación a la condesa doña Aldonsa Crespí de Valldaura y sus esfuerzos por defender a su hija Isabel, de realizar un breve recorrido por el entorno más inmediato de la Casa Carroz, a la que se veía vinculada por su matrimonio con don Francisco Carroz, conde de Cirat. Asimismo, esto también nos permitirá detenernos en otras mujeres asociadas a la familia por el mismo sacramento, que sufrieron de modo similar la indefensión a la que el sistema las relegaba cuando se veían alejadas de cualquier figura masculina que las amparara.

Cuando el título de conde de Cirat todavía no se encontraba entre los méritos de los Carroz, sí que eran varios los cargos que se podían hallar en los curricula de sus miembros. Los primeros que hacen su aparición en la documentación son don Luis Carroz de Villaragut, hermano de don Galcerán Carroz Pardo de la Casta, pues durante el siglo XVI, tanto él como 


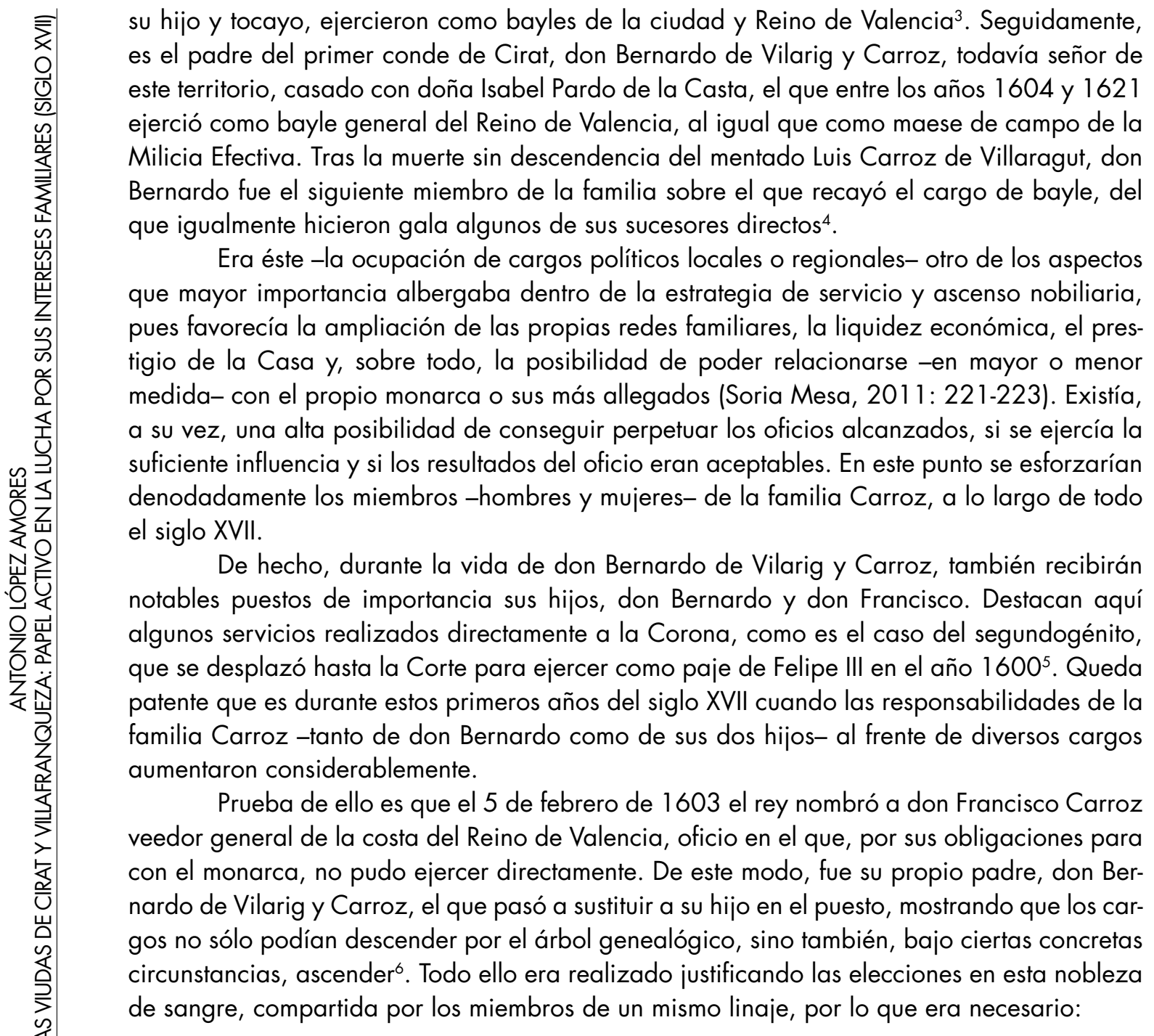

218

\footnotetext{
3 Archivo de la Diputación de Castellón [ADC], Donación del Conde de Cirat, caja 17, leg. 50, documento 1

4 Ibídem y Real Academia de la Historia [RAH], signatura 9-320, fo 28.

5 ADC, Donación del Conde de Cirat, caja 17, leg. 50, documento 3.

6 ADC, Donación del Conde de Cirat, caja 17, leg. 46, documento 1.
}

Dossiers Feministes, 21, 2016, 215-231 - ISSN: 1139-1219 - DOI: http://dx.doi.org/10.6035/Dossiers.2016.21.13 
nombrar persona de suficiencia experiencia y confiança para que sirva el dicho officio de veedor general, tiniendo satisfación de que en la de vos, don Vilarig Carroz, padre del dicho don Francisco Carroz, concurren estas y otras buenas partes ${ }^{7}$

El condado de Cirat fue otorgado en 1626 a favor de don Bernardo de Vilarig y Carroz, hermano de don Francisco (Guardiola y Spuche, 2004: I, 240). El padre de ambos había fallecido y el primogénito había heredado no sólo el vínculo de los Carroz, sino también el oficio de bayle general, cargo que desempeñó hasta $1637^{8}$.

Es en la familia más cercana de don Bernardo donde podemos hallar uno de los ejemplos que muestran el estado desprotegido en el que se encontraban las esposas tras la muerte del marido, como veremos más adelante en el modelo de otra de las condesas viudas de Cirat. El primer matrimonio de este noble fue con doña Vicenta Villarrasa ${ }^{9}$ y, en segundo lugar, casó con doña Magdalena Martínez de Vera ${ }^{10}$, hija de don Pedro Martínez de Vera -receptor de la Baylía General del Reino y administrador de las salinas de la Mata entre 1612 y 1627 y doña Isabel Fernández de la Mesa"1", enlace para el cual fue necesaria la dispensa real, otorgada en 1635, por ser don Bernardo caballero de la orden de Santiago ${ }^{12}$.

FIGURA 1: Familia próxima de doña Magdalena Martínez de Vera (s. XVII)

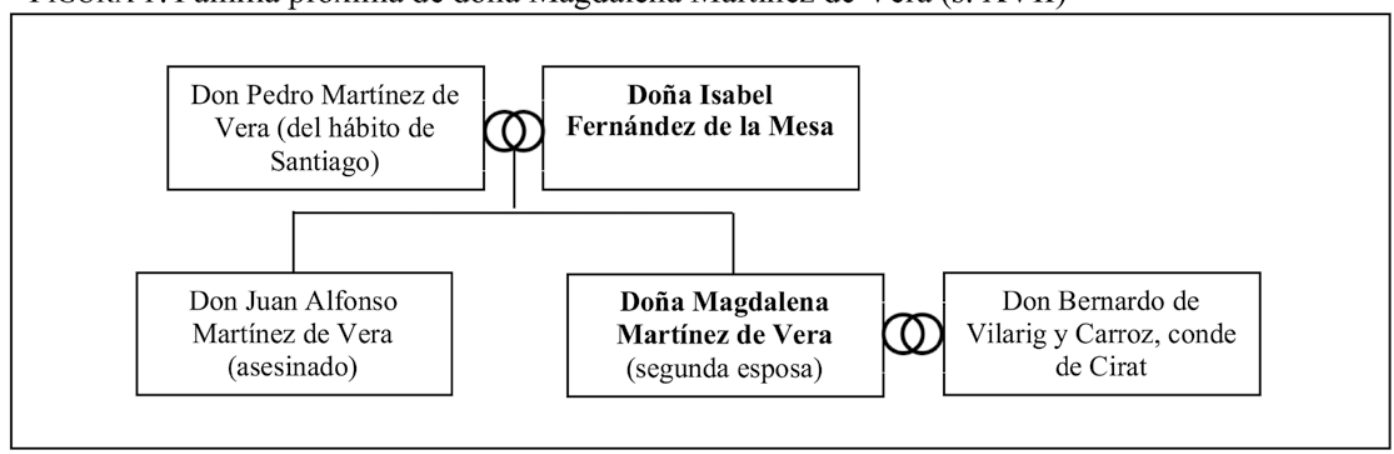

Fuente: elaboración propia en base a $R A H$, signatura 9-320, $\mathrm{f}^{\mathrm{0}} 28 ; A D C$, Donación del Conde de Cirat, caja 17, leg. 13, documento 1 y $A C A$, Consejo de Aragón, leg. 892, doc. 193.

\footnotetext{
7 lbídem.

8 ADC, Donación del Conde de Cirat, caja 17, leg. 50, documento 1.

$9 R A H$, signatura 9-320, fo 28.

10 Véase la Figura 1: Familia próxima de doña Magdalena Martínez de Vera (s. XVII)

11 Archivo de la Corona de Aragón [ACA], Consejo de Aragón, leg. 892, doc. 193.

12 ADC, Donación del Conde de Cirat, caja 17, leg. 13, documento 1.
} 


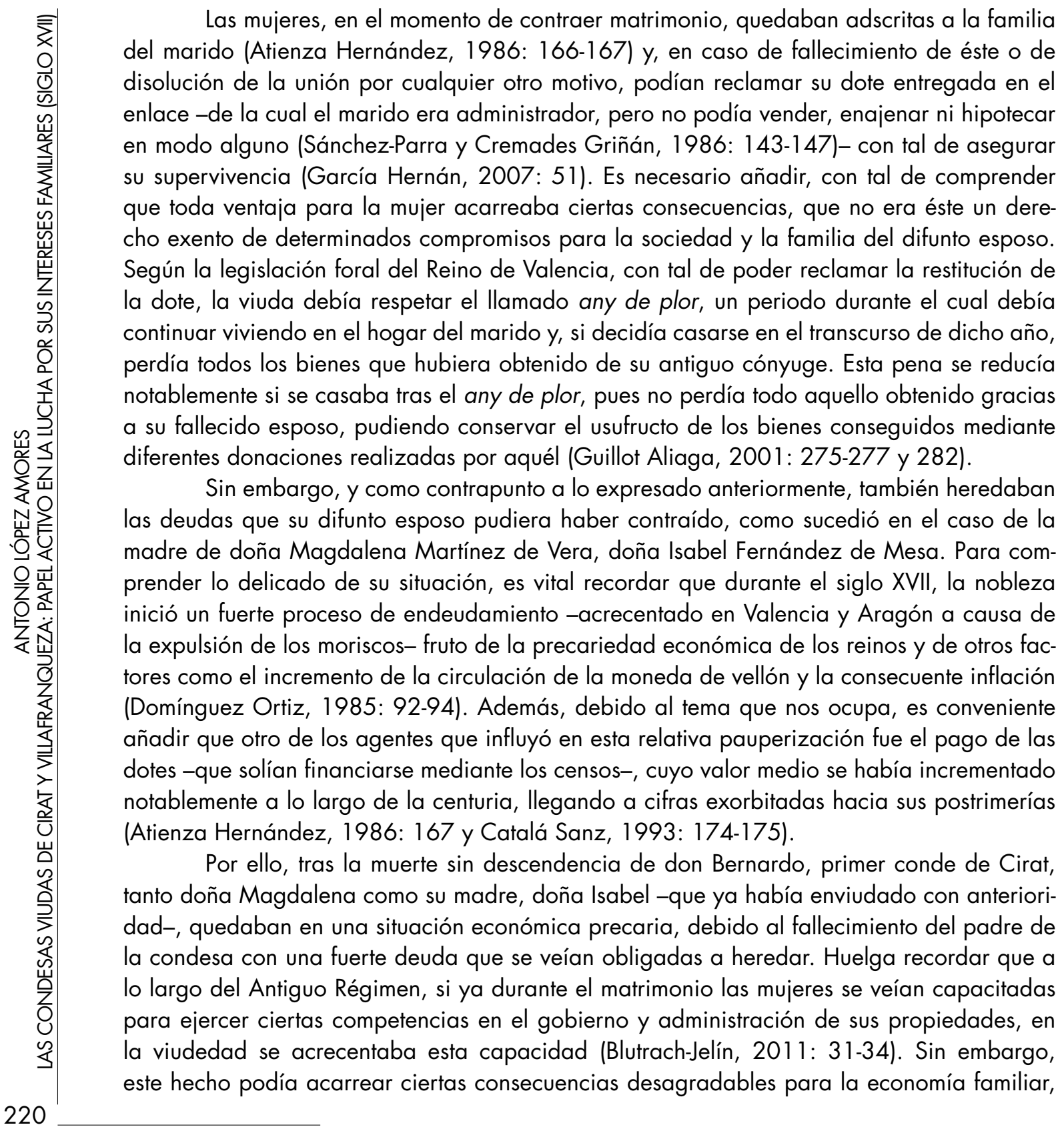

Dossiers Feministes, 21, 2016, 215-231 - ISSN: $1139-1219$ - DOI: http://dx.doi.org/10.6035/Dossiers.2016.21.13 
debido a las deudas acumuladas y a las nuevas responsabilidades adquiridas. A su vez, la situación para la familia se vio fuertemente agravada tras el asesinato del hijo primogénito, don Juan Alfonso Martínez de Vera, -caballero del hábito de Santiago y receptor de la Baylía de Alicante $^{13}-$, que se había encargado de las inestables cuentas tras el óbito del padre ${ }^{14}$ :

ha sido tan grande la perdisión de su Casa que en el año 15 hizo executar unos deudores de vuestra majestad y por esto le mataron un hermano, y en Valencia le an muerto un solo hijo que tenía, y a quedado tan desanparada y sin persona que la pueda ayudar, y sin hazienda ${ }^{15}$

Estas circunstancias habían confluido en el embargo de bienes y hacienda de madre e hija, dejándolas en una situación de «suma necesidad» a las «pobres viudas», razón por la cual, en 1645, iniciaban una súplica por la cual pedían que finalizase la incautación a la que se habían visto sometidas y se asignase un juez en Valencia con tal de que se pudiese atender su particular caso ${ }^{16}$.

FIGURA 2: Entorno familiar de la viuda doña Aldonsa Crespí de Valldaura (s. XVII)

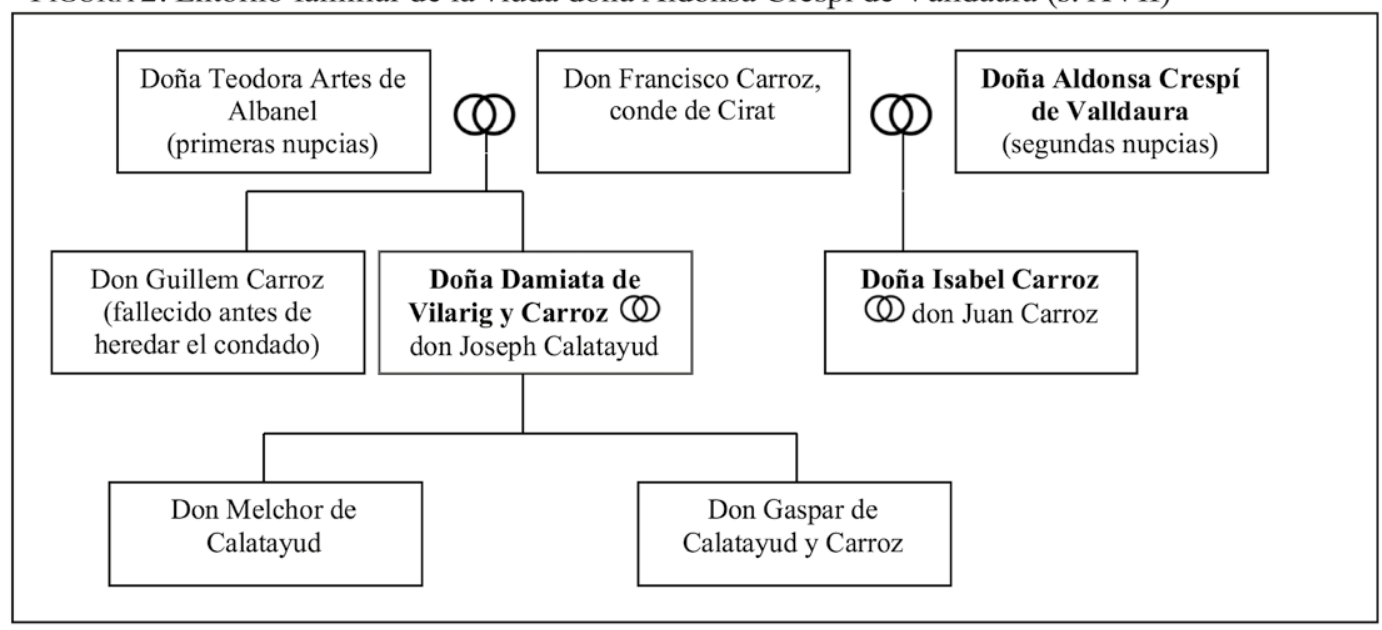

Fuente: elaboración propia en base a $A D C$, Donación del Conde de Cirat, caja 13, leg. 1, documento 1 y $R A H$, Signatura 9-320, $\mathrm{f}^{\mathrm{D}} 28$.

13 Concedido el 14 de marzo de 1628. ACA, Consejo de Aragón, leg. 929, doc. 26.

14 ACA, Consejo de Aragón, leg. 892, doc. 193.

15 Ibídem.

16 Ibídem. 
A lo largo de esta dura cadena de sucesos, el condado de Cirat pasó, debido a la muerte de don Bernardo sin descendencia, al hermano de éste, don Francisco Carroz, que seguía desempeñando sus funciones como veedor general de la costa del Reino de Valencia. Así, a lo largo de su vida, contrajo primeras nupcias con doña Teodora Artes de Albanel y segundas nupcias con doña Aldonsa Crespí de Valldaura ${ }^{17}$, teniendo como descendencia a un hijo y una hija con la primera -don Guillem, que no llegaría a heredar el condado debido a su prematura muerte, y doña Damiata-, y otra hija con la segunda -doña Isabel (Guardiola y Spuche, 2004: I, 240) ${ }^{18}$.

Mientras el primogénito todavía vivía, Felipe IV le hizo merced del cargo de veedor general de la costa -como ya venía siendo tradición en la familia-, de la encomienda de Ademuz y de Castelfabib y de 800 libras de pensión ${ }^{19}$. Sin embargo, su muerte complicó la pervivencia de dicho oficio en la familia. La solución fue socorrida: transmitir el puesto a través de su hija, doña Damiata. Así, don Francisco pidió al rey que le otorgase el oficio de veedor general de la costa al marido de su hija, don Joseph Calatayud, señor de Agres y Sella ${ }^{20}$.

No obstante, otro óbito, esta vez el del propio conde, supuso una nueva cortapisa al proceso, dejando a su mujer viuda y a una hija -doña Isabel- soltera y sin recursos. Esta situación de desamparo fue resuelta con la concesión del cargo de veedor general a don Joseph de Calatayud, esposo de doña Damiata Carroz, con la salvedad de que los emolumentos recogidos de su ejercicio deberían ir a parar a la viuda y a la dote de la hija soltera ${ }^{21}$. Este patrón pone de manifiesto la fuerte dependencia que podían llegar a experimentar las mujeres hacia sus maridos o padres, menor en el caso de aquéllas que quedaban viudas, pero notable para las hijas solteras, cuyas únicas salidas eran el matrimonio o el ingreso en el convento, siendo para ambas opciones necesario un desembolso económico previo (Atienza Hernández, 1986: 167). Esta característica de solidaridad, sin embargo, no es algo puntual, sino que viene recogida en los fueros, de modo que se debía proveer, como mínimo, de cobijo, vestimenta y alimento, tanto los padres respecto a sus hijos como de éstos para sus progenitores (Benítez Sánchez-Blanco, 1992: 53-54).

Una consulta al Consejo de Aragón, datada del 22 de mayo de 1671, muestra el denodado interés de la viuda doña Aldonsa Crespí de Valldaura en asegurar el bienestar de

\footnotetext{
17 Véase la Figura 2: Entorno familiar de la viuda Aldonsa Crespí de Valldaura (s. XVII).

$18 R A H$, signatura 9-320, fo 28.

$19 A D C$, Donación del Conde de Cirat, caja 3, leg. 17, documento 3 y ADC, Donación del Conde de Cirat, caja 17, leg. 50, documento 3 .

20 ADC, Donación del Conde de Cirat, caja 3, leg. 17, documento 3.

21 Ibídem.
}

Dossiers Feministes, 21, 2016, 215-231 - ISSN: 1139-1219 - DOI: http://dx.doi.org/10.6035/Dossiers.2016.21.13 
la que era su hija biológica: doña Isabel. En ella se relata cómo, también a su hija, le había sido otorgada la merced del oficio de veedor general de la costa del Reino de Valencia, que recaería en la persona de su futuro marido, don Juan Carroz. De este modo, la condesa intervino a favor de su única hija, con tal de que se le dejase, "para sus alimentos», con las trescientas libras que traía aparejado el oficio, mientras durase su vida ${ }^{22}$.

Tras la muerte de don Joseph de Calatayud, sería su hijo primogénito, don Melchor, conde de Cirat, el que heredaría el puesto de veedor general. De este modo, ejerció sus responsabilidades «durante su vida sin emolumento ni salario alguno», pues éstos seguían derivándose hacia su tía, doña Isabel. A la muerte de este, junto con la transferencia del condado a su hermano, don Gaspar, también vendría aparejada la veeduría general de la costa, con las mismas circunstancias, es decir, sin que su responsable recibiese «premio ni remuneración alguna» ${ }^{23}$.

Finalmente, sería este conde, don Gaspar de Calatayud y Carroz, el que realizaría una súplica, en la que exponía todos los servicios realizados por su linaje, con tal de argumentar que la perpetuación del oficio de veedor general estaba más que justificada en la sangre de su familia, por lo que pedía que el servicio se pudiera prolongar durante dos generaciones más. Al mismo tiempo, también reclamaba los emolumentos correspondientes al puesto, una vez que su beneficiaria, doña Isabel Carroz, falleciese ${ }^{24}$.

Todo este desarrollo de acontecimientos muestra -al menos en este caso en el que nos ubicamos, de la familia Carroz- dos aspectos fundamentales del desarrollo familiar de la nobleza y del papel que las mujeres desempeñaban en él. En primer lugar, queda patente que la situación de viudez fue una espada de doble filo para las mujeres, fuertemente influenciada por su nivel económico (Guillot Aliaga, 2001: 269), pues por un lado les permitía una mayor independencia -muestra de ello son los diversos recursos presentados por ellas con tal de subsanar su precaria situación o velar por sus intereses-y, al mismo tiempo, las hacía más vulnerables a las inclemencias del sistema -como prueba la adquisición de deudas que difícilmente podían subsanar.

En segundo lugar, la documentación consultada refleja un sentimiento de solidaridad que, si bien respaldado por los fueros, tiene como fin el apoyo de los diferentes miembros de la familia; sobre todo aquéllos que -como las hijas solteras o, en ocasiones, las viudas- se encontraban en una situación de mayor desventaja en comparación con el resto de sus familiares. Este fenómeno es particularmente notable -si bien resulta lógico- en aquellas circuns-

22 ACA, Consejo de Aragón, leg. 741, doc. 100

$23 A D C$, Donación del Conde de Cirat, caja 3, leg. 17, documento 3

$24 \mathrm{lbi}$ idem. 


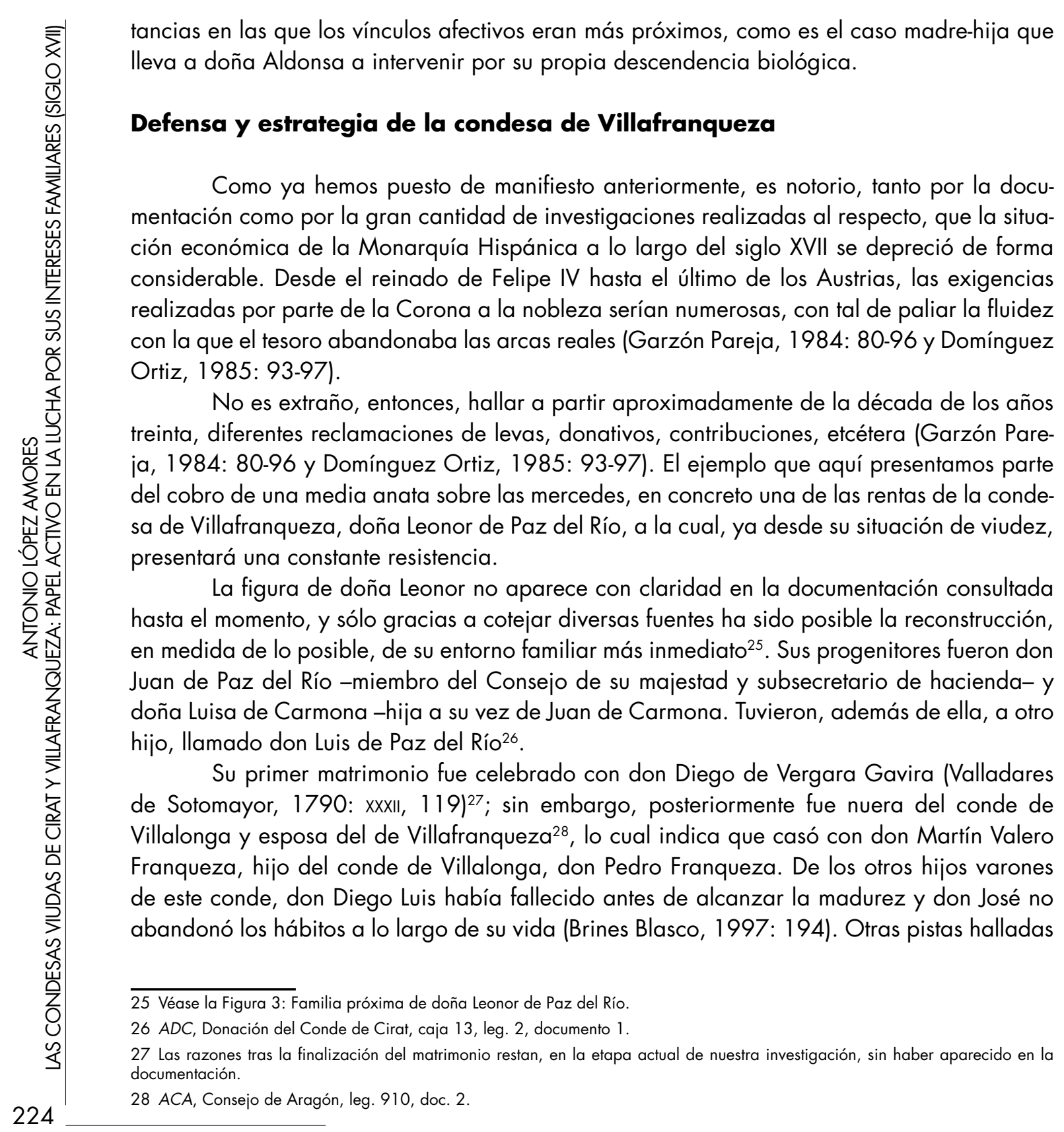

Dossiers Feministes, 21, 2016, 215-231 - ISSN: 1139-1219 - DOI: http://dx.doi.org/10.6035/Dossiers.2016.21.13 
al encontrar diferentes referencias a su esposo y al padre del mismo: «en recompensa y satisfación de diferentes rentas que gozava el conde de Villalonga su suegro y se adjudicaron al Patrimonio Real»; o al hablar directamente de su suegro: «cuios servicios fueron tan notorios como también los grandes travajos que padeció haviéndose manifestado después la violencia de ellos y su inocencia ${ }^{29}$, indican inequívocamente que se trata del antiguo consejero ${ }^{30}$.

FIGURA 3: Familia próxima de doña Leonor de Paz del Río (aprox. 1600-1680)

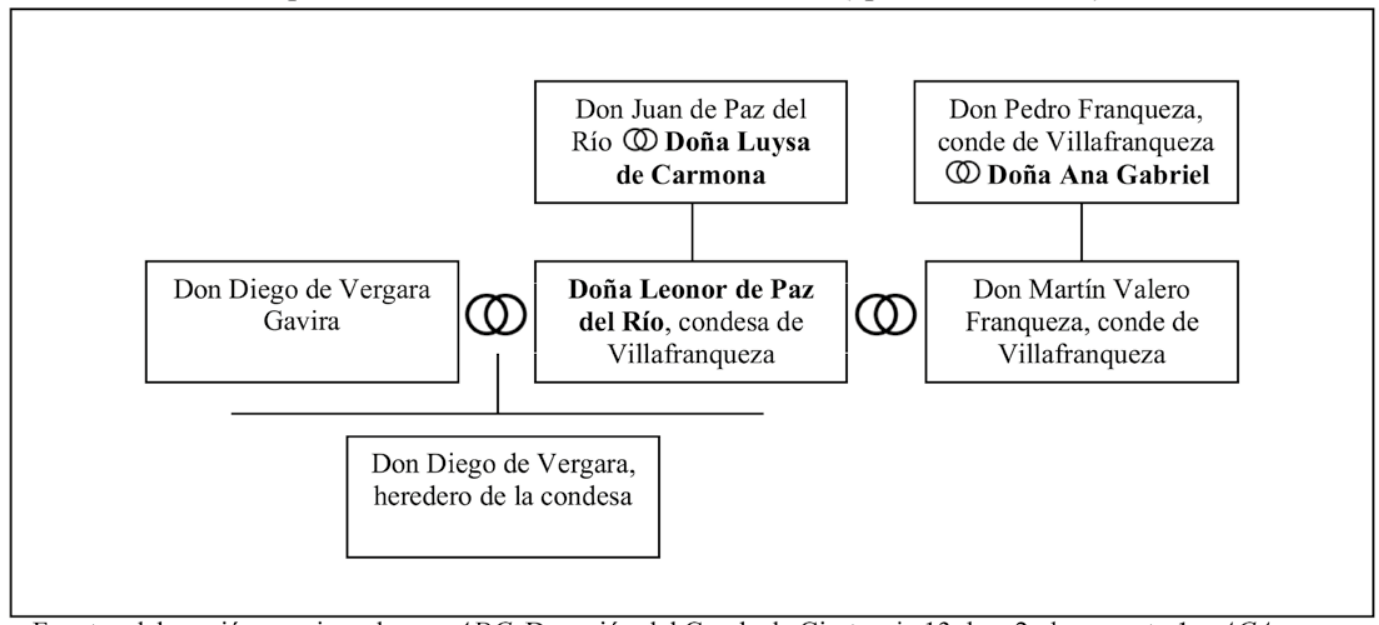

Fuente: elaboración propia en base a $A D C$, Donación del Conde de Cirat, caja 13, leg. 2, documento 1 y $A C A$, Consejo de Aragón, leg. 910, doc. 2.

Del enlace contraído con su primer marido tuvo dos hijos (Valladares de Sotomayor, 1790: xxxII, 209), de los cuales la documentación muestra que uno de ellos fue llamado don Diego de Vergara ${ }^{31}$. Al mismo tiempo, el traspaso del título a otras ramas del linaje de los Franqueza muestra que su segundo matrimonio finalizó sin descendencia.

La condesa, que había enviudado en el año 1658 (Brines Blasco, 1997: 194), vivió de diversas rentas que había ido acumulando a lo largo de su vida, entre las que destacaba una de 1.000 ducados de plata, obtenida gracias a la merced del rey. Ésta provenía de su

29 ACA, Consejo de Aragón, leg. 647, doc. 52.

30 Para más información acerca del juicio realizado al secretario don Pedro Franqueza, a raíz del enriquecimiento personal llevado a cabo en servicio a la Monarquía, remitimos a Gómez RIVERO, Ricardo (2001-2003): «El juicio al secretario de estado Pedro Franqueza, conde de Villalonga», lus fugit: Revista interdisciplinar de estudios histórico-jurídicos, 10-1 1, Zaragoza, Universidad de Zaragoza e Instituto Fernando el Católico, pp. 401-531.

31 ACA, Consejo de Aragón, leg. 647, doc. 52. Realizamos esta deducción gracias al hecho de que este hijo no pudo heredar el condado de Villafranqueza -por ser de otra familia- y debido a que su propio apellido coincide con el del primer esposo de doña Leonor. 


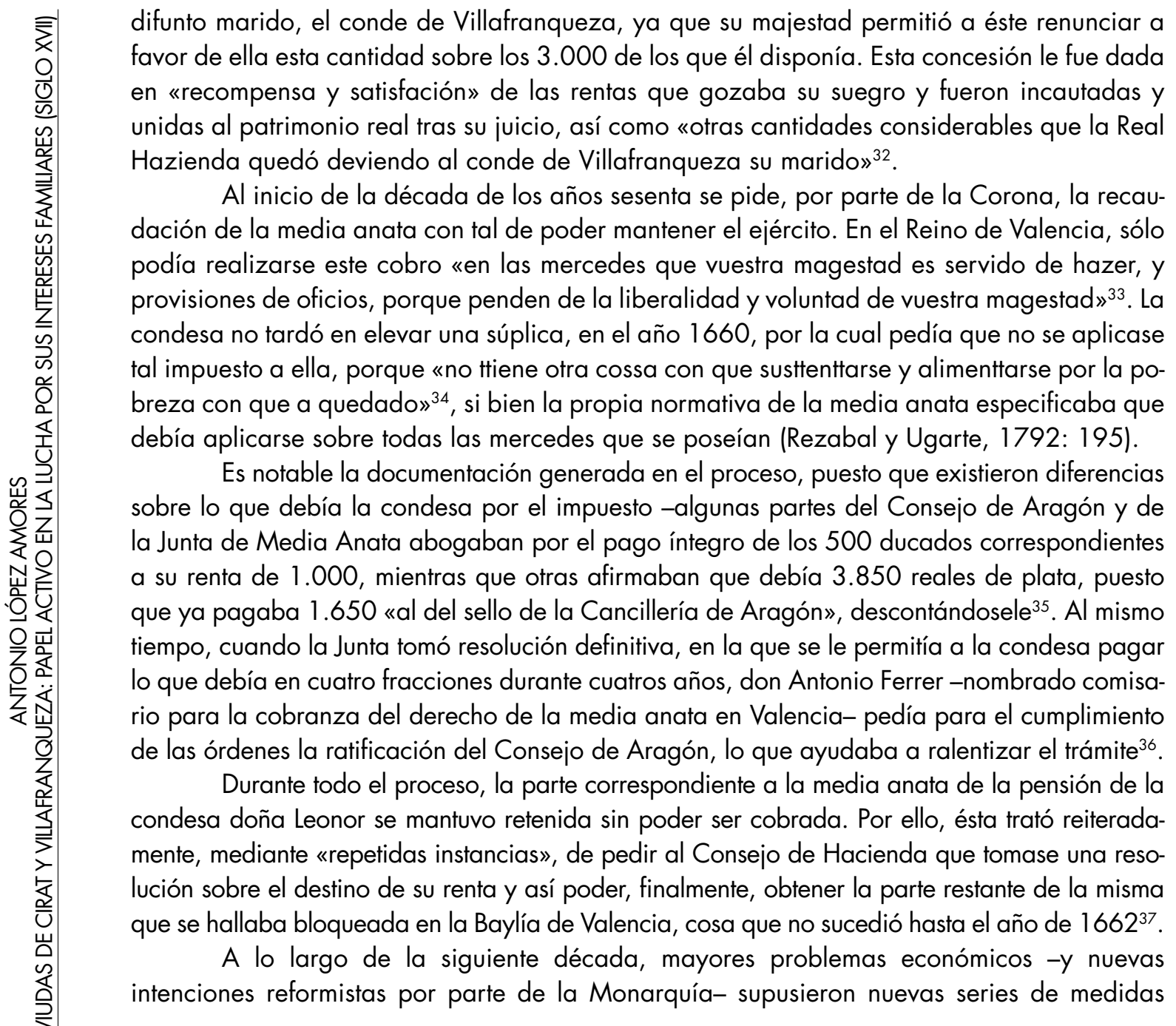

226

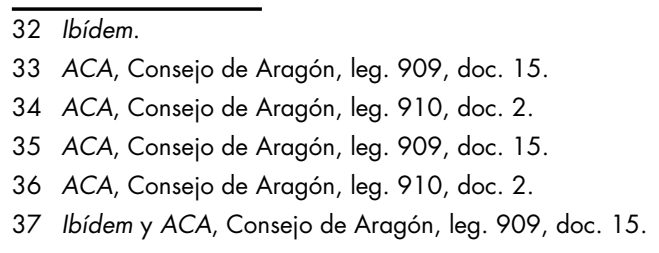

Dossiers Feministes, 21, 2016, 215-231 - ISSN: 1139-1219 - DOI: http://dx.doi.org/10.6035/Dossiers.2016.21.13 
económicas que verían sus efectos plasmados a largo plazo (Ribot García, 2006: 214-218). Una de éstas fue la reforma de las mercedes, que decretó que éstas debían ser reducidas a la mitad, por lo que también se vio afectada doña Leonor de Paz del Río, respecto a la misma renta por la que había realizado tantas instancias anteriormente.

En el año 1670 ya había realizado una petición con tal de «no ser comprehendida en la orden general y reforma de dichas mercedes graciosas», por lo que en base a sus necesidades, y por hallarse «con crecida hedad y ciega» se le concedió una prórroga de un año. No obstante, nuevas consultas se generan cuando el Consejo de Aragón recibe noticias de nuevas peticiones de la condesa, esta vez «con maiores ahogos y nuebas enfermedades», suplicando se le mantuviese la dicha renta, intacta, durante el resto de sus días ${ }^{38}$.

El Consejo se mostró abiertamente opuesto a esta opción, aconsejando de este modo al monarca, pues la situación económica de la Baylía General de Valencia había visto tiempos mejores: la falta de liquidez era notable y existían dificultades para hacer frente a los gastos de la administración de justicia y a los salarios de los ministros de la Audiencia. Su veredicto, en definitiva, fue que la condesa podía sustentarse perfectamente con los quinientos ducados de plata que le quedarían tras la reforma. La decisión regia sería, nuevamente, la reserva durante otro año.

En 1673, nos encontramos de nuevo ante la misma situación, donde la condesa argumentaba que no se la debía incluir «en dicha reforma por ser ésta de diferente calidad que otras por ser alimentos suyos, y hallarse viuda, enferma y ciega». La opinión del Consejo siguió manteniéndose firme, dada la apurada situación de la Baylía General de Valencia, y así aconsejaron a la regente, Mariana de Austria. La decisión de ésta, sin embargo, fue la misma que en los dos casos anteriores: una prórroga durante un año más ${ }^{39}$.

Sin embargo, es la última consulta generada, a finales de ese mismo año, en la que la condesa alegó unos nuevos motivos por los que realizar la petición:

y respecto de hallarse la condesa tan impedida, sin vista y con mucha hedad y en la cama, suplica a vuestra magestad que los dichos mil ducados de renta se traspasen en don Diego de Vergara Gabira, su hixo legítimo, para que los goze en la misma conformidad que ella y con la propria graduazión por no tener otra cosa que dejarle para su sustento ${ }^{40}$.

Nuevamente, la respuesta del Consejo fue desaconsejar las pretensiones de la condesa, pues suponía perpetuar una «renta de tan grande consideración» en la persona de su

38 ACA, Consejo de Aragón, leg. 647, doc. 52

39 Ibídem.

40 Ibídem. 


\begin{abstract}
= hijo, con el consecuente compromiso durante varios años más. Lo cual, sumado con el estado desgastado de la Baylía General de Valencia, no hizo sino acrecentar la intensidad de la opinión de los consejeros. Esta vez, no obstante, la regente cedió a los argumentos expuestos por estos últimos, acabando así con el anhelo de la condesa y negándole a su hijo y heredero toda posibilidad de heredar las rentas de su madre ${ }^{41}$.

Como ya expresamos más arriba, las viudas gozaban de una mayor independencia, pareja a una mayor vulnerabilidad, como puede comprobarse por los distintos casos presentados hasta este punto. Sin embargo, en éste puede resultar evidente que el móvil de la condesa de Villafranqueza no es, exclusivamente, el mantener su renta de 1.000 ducados de plata intacta, sino también el tratar de hacerla extensiva a su único hijo, una vez ella falleciese.

Por tanto, al margen de la propia subsistencia, existe una visión estratégica a la hora de remitir las súplicas, propia también de la época y de la situación femenina, pues tras varias prórrogas -en las que la regente había acabado siempre dando su beneplácito a lo que ella requería, yendo en contra de la opinión del consejo- realiza una petición diferente, no por ella sino por su hijo. Como era habitual, la intención de perpetuar la renta de 1.000 ducados sin recorte alguno -que a su vez provenía de su marido y suegro- en la figura de su hijo fue, posiblemente, el móvil de mayor importancia que llevó a doña Leonor de Paz del Río a realizar numerosas súplicas, con tal de defender sus intereses propios y los de su única descendencia.
\end{abstract}

\title{
Conclusiones
}

No resulta arduo, en los casos anteriormente expuestos, vislumbrar los patrones que conforman el marco restrictivo al que se veían adscritas las mujeres del Antiguo Régimen. Desde cualquiera que fuera su situación -hijas, esposas o viudas- destacan sobremanera dos factores estrechamente interrelacionados: la precariedad, pues ante la muerte del padre 0 esposo (o, en según qué circunstancias, incluso otros familiares) podían ver su futuro truncado con facilidad y caer en un escenario de indefensión; y la dependencia, siempre hacia una figura masculina, que debía velar por sus planes y asegurar su supervivencia incluso tras la propia muerte.

Sin embargo, al menos en los diferentes ejemplos que la documentación nos ha permitido mostrar aquí, también es posible apreciar que existían comportamientos de preocupación y solidaridad hacia estas situaciones de desamparo, más notables en los lazos familiares más directos. De todo lo anterior puede extraerse la conclusión de que, junto a la profunda y 
arraigada desigualdad que jalonaba el sistema, coexistía un conocimiento activo y explícito de la precariedad que sufría la mujer en el Antiguo Régimen.

Como muestra de ello podemos emplear el constante esfuerzo que dedicó doña Aldonsa Crespí en asegurar el porvenir y bienestar de su hija, y al que acabaron contribuyendo varios miembros de la familia, hasta el fin de sus días. Del mismo modo, el constante apoyo que recibe doña Leonor de Paz del Río por parte de las autoridades regias $-y$, de hecho, en contra de la voluntad de los consejeros- no es sino otro ejemplo adicional, otra muestra más, que pone de relevancia que la indefensión a la que se veían reducidas las mujeres ante la ausencia del hombre era vox populi. Así, incluso con la pertenencia a la clase privilegiada nobiliaria, las viudas y las huérfanas no se veían libres de la amenaza de la pobreza y la desgracia.

Ante ello, resulta lógico y comprensible que se elaborasen, por parte de las afectadas y por parte de las propias Casas, estrategias -propias e inherentes a la época- con tal de paliar los posibles contratiempos que el futuro pudiese aguardar a las mujeres de la familia. Estas herramientas permitían plantear una defensa ante el sistema en caso de ser necesario, es decir, cuando se preveía que éste podía causar problemas o desgracias en cualquiera de los miembros de la familia, siendo ellas particularmente susceptibles a los mismos. En definitiva, si bien la viudedad podía conferir una limitada gama de recursos, traía consigo asociadas ciertas debilidades, que podían afianzarse en un contexto precario. Sin duda, en base a lo explicitado en las páginas precedentes, podemos afirmar que los fenómenos económicos, políticos, sociales e incluso naturales podían golpear a las mujeres con mayor dureza y contundencia.

\section{Referencias y bibliografía}

AtienZA Hernández, Ignacio (1986): «Las mujeres nobles: clase dominante, grupo dominado. Familia y orden social en el Antiguo Régimen», en GarcíA-Nieto París, María Carmen (coord.): Ordenamiento jurídico y realidad social de las mujeres: siglos XVI a XX: actas de las IV Jornadas de Investigación Interdisciplinaria, Madrid, Universidad Autónoma de Madrid y Seminario de Estudios de la Mujer, pp. 149-168.

(1998): "La memoria construida. Nobleza y genealogía de la Casa y la Villa de Osuna», Apuntes 2: Apuntes y Documentos para una Historia de Osuna, 2, Osuna, Ayuntamiento de Osuna y Fundación de Cultura García Blanco, pp. 7-26. 


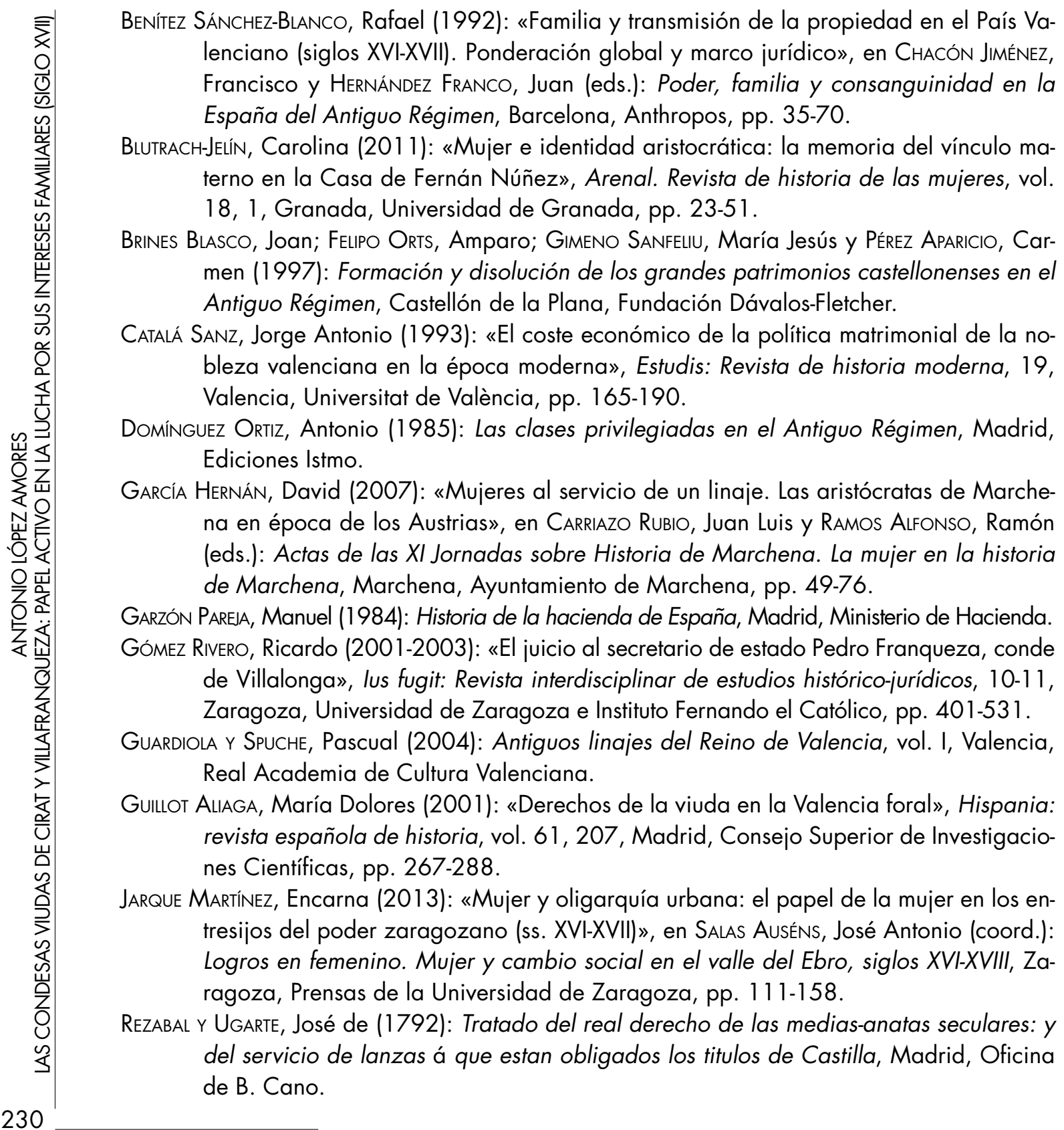

Dossiers Feministes, 21, 2016, 215-231 - ISSN: $1139-1219$ - DOI: http://dx.doi.org/10.6035/Dossiers.2016.21.13 
Ribot García, Luis Antonio (2006): El arte de gobernar: estudios sobre la España de los Austrias, Madrid, Alianza Editorial.

Sánchez-Parra García, María del Pilar y Cremades Griñán, Carmen María (1986): «Los bienes de la mujer aportados al matrimonio. Evolución de la dote en la Edad Moderna», en Ordenamiento jurídico y realidad social de las mujeres: siglos XVI a XX: actas de las IV Jornadas de Investigación Interdisciplinaria, Madrid, Universidad Autónoma de Madrid y Seminario de Estudios de la Mujer, pp. 137-148.

SORIA MESA, Enrique (2011): La nobleza en la España moderna, Madrid, Marcial Pons Historia.

VAlladares de Sotomayor, Antonio (1790): Semanario erudito, que comprehende varias obras ineditas, criticas, morales, instructivas, politicas, historicas, satiricas, y jocosas, de nuestros mejores autores antiguos, y modernos, Madrid, Imprenta y librería de Alfonso López.

Recibido el 20 de enero de 2016

Aceptado el 15 de febrero de 2016 BIBLID [1 139-1219 (2016) 21: 215-231 